\title{
Depression in Cancer Care
}

\author{
Daisuke Fujisawa \\ ${ }^{1}$ Department of Neuropsychiatry, Keio University School of Medicine, Tokyo, Japan \\ ${ }^{2}$ Palliative Care Center, Keio University Hospital, Tokyo, Japan
}

(Received for publication on August 6, 2017)

(Revised for publication on September 28, 2017)

(Accepted for publication on October 5, 2017)

(Published online in advance on October 14, 2017)

\begin{abstract}
Depression is common among cancer patients and their families, and may lead to substantial clinical consequences. Clinicians should routinely screen cancer patients for comorbid depression and should provide appropriate care at both primary and specialized care levels. Good quality care is beneficial not only for cancer patients themselves but also for their family members. It includes good communication between patients and health providers, and addressing of unmet needs of cancer patients. Specialized care comprises pharmacotherapy and psychotherapy. The advancement of psychotherapy for cancer patients parallels the advancement of general psychotherapy. Among the many types of psychotherapies, mindfulness-based interventions have been attracting growing attention. Some relevant studies that have been conducted in Keio University Hospital are described herein. (DOI: 10.2302/kjm.2017-0010IR; Keio J Med 67 (3) : 37-44, September 2018)
\end{abstract}

Keywords: cancer, depression, family, mental health

\section{Introduction}

The Global Burden of Disease in 2013 study established that there were 14.9 million incident cancer cases and 8.2 million cancer deaths per year, composing the second leading cause of death worldwide. ${ }^{1}$ Despite recent substantial progress in prevention and treatment, the cancer burden is increasing owing to a growing and aging global population and to lifestyle-associated risk factors (e.g., smoking, obesity, and dietary patterns). Cancer caused 196.3 million disability-adjusted life years in 2013. In Japan also, cancer is one of the leading causes of disease burden, affecting approximately half the population lifetime wise and resulting in cancer death in about one-third of the population. ${ }^{2}$

Cancer not only threatens patients' survival but also affects their quality of life. ${ }^{3-5}$ Numerous studies have demonstrated an elevated risk of psychological distress among cancer patients compared with the general population. ${ }^{6,7}$ The markedly elevated incidences of suicide and cardiovascular events that are observed soon after cancer diagnosis reflect the major impact the disease has on patients' psychological state. ${ }^{8}$ Of the various psychiatric conditions, depression is one of the leading causes of functional disability. In this article, the author reviews depression among cancer patients, focusing on its prevalence, risk factors, impact, and optimal management.

\section{Prevalence}

A recent meta-analysis showed the prevalence of major depression among cancer patients according to stringent criteria to be $16.3 \%$ (13.4-19.5\%). Another 19.2\% (9.1$31.9 \%$ ) of cancer patients suffer from minor depression or subthreshold depression [a milder type of depression that does not meet the criteria of major depression but can impair the functioning and quality of life (QoL) of patients]. ${ }^{9}$ Furthermore, a cross-sectional study conducted in Keio University Hospital in 2007 revealed that severe psychological distress was observed in $28.0 \%$ of all hospitalized cancer patients, in contrast with $8.5 \%$ of non-cancer patients, despite the two groups having similar physical 
symptom burdens. ${ }^{10}$

Depression can occur in patients with any type of cancer and at any stage of the illness. Key risk factors for developing depression include, but are not limited to, a history of depression, lower levels of social support, advanced stages of illness, higher symptom burden, and more frequent unmet needs. ${ }^{7,9-12}$ Other predisposing risk factors include younger age, neurotic personality, and low education history: ${ }^{12-14}$ however, these predisposing factors are unmodifiable, and, therefore, clinicians should focus on the modifiable key risk factors that are mentioned above.

\section{Impact of Depression}

Depression not only causes suffering to patients, but it also impairs multiple aspects of patients' well-being. Even a mild level of depression causes significant decrements in QoL that are comparable to decrements due to major physical symptom burden and decreased performance status. ${ }^{15}$ In many studies, depression is associated with shorter survival in cancer patients, both as a result of death by cancer and death by other causes, although conflicting results exist. ${ }^{16-18}$ Lower survival in patients with depression is partly explained by their poorer adherence to cancer treatment, ${ }^{19}$ poorer self-care (e.g., an unfavorable life-style such as decreased levels of physical exercise ${ }^{20}$ and higher alcohol and tobacco consumption), ${ }^{21}$ and consenting to medical decisions which may shorten life (e.g., receiving chemotherapy at the very end of life, which can adversely affect survival). ${ }^{22}$ In clinical settings, patients with depression tend to stay longer in hospital. ${ }^{23,24}$ Depression often increases sensitivity to and monitoring of physical sensations and thereby may increase pain. ${ }^{25}$ Depression is a large contributor to the wish for hastened death (e.g., suicide, physician-assisted suicide, euthanasia, and rejection of proper treatment). ${ }^{26}$ There is some evidence that depression decreases immune function, although its relationship with cancer prognosis remains unclear. ${ }^{27}$

\section{Diagnosis}

Depression is a syndrome with symptoms encompassing emotional, cognitive, behavioral, and somatic aspects. It is a spectrum of symptoms, where normal sadness or grief occurs at the milder end, and major depressive disorder at the opposite, more severe end. Minor or subthreshold depression lies in the middle.

Depression is diagnosed by the assessment by skilled clinicians of a series of depressive symptoms based on stringent diagnostic criteria [usually the Diagnostic and Statistical Manual of Mental Disorders, fifth edition $(\text { DSM-5 })^{28,29}$ or the International Classification of Diseases, tenth edition (ICD-10)]. ${ }^{28}$

Major depressive disorder is a diagnostic category characterized by five or more of nine depressive symptoms being present for most of the day for at least 2 weeks. At least one of those five symptoms needs to be depressed mood or anhedonia (decreased interest or diminished sense of pleasure). The other symptoms include decreased energy, marked changes in appetite (decrease or increase of appetite, which can be allied with changes in body weight), sleep disturbance (either insomnia or hypersomnia), psychomotor agitation or retardation (i.e., patients may objectively look irritable or be slow in actions), feelings of worthlessness or guilt, difficulty concentrating, and suicidal ideation. ${ }^{29}$

The diagnostic term "adjustment disorder" is often used for milder forms of depression. This diagnostic category refers to a state of distress that is greater than normally expected from exposure to a certain stressor, and may present with depressive symptoms. However, difficulty in defining normative distress in the context of cancer raises questions about its diagnostic validity.

If a patient has two to four of the symptoms above for at least 2 weeks, he or she can be diagnosed as having minor (or subthreshold) depression. Although minor depression is not a well-established diagnostic criteria, it is known to be associated with significant impairment of QoL and can be critical, especially among vulnerable populations such as individuals with cancer. Therefore, patients with minor depression are considered an important target of treatment if significant functional disability persists. ${ }^{15}$

Differentiation between major depression and adjustment disorder is often ambiguous. The rule of thumb is that, although life stressors may seem to provide "good reasons" for sadness, the diagnosis of depression should not be withheld if a patient meets the criteria for major depression. Patients with more severe and more pervasive symptoms tend to be diagnosed with major depression rather than adjustment disorder or "normal" reactions to stressful events. The following symptoms strongly suggest that the patient has major depression: loss of emotional reactivity to good news (e.g., a patient does not feel joy in response to hospital visits by their loved ones), irrational sense of self-guilt (e.g., a patient strongly believes that his/her cancer is a "punishment" for his/her past deeds), and persistent suicidal thoughts.

Depression can be masked. Some patients, especially older patients and those with severe depressive symptoms, may not explicitly admit to lowered mood, and this can make the assessment difficult. The following objective appearance and behavior of patients may be signs for depression: social withdrawal (e.g., a patient stops going out or meeting with friends as he or she used to do), nonparticipation in medical care (e.g., a patient refuses rehabilitation), diminished positive emotional reactions (e.g., a patient does not smile or is unable to be cheered up), and demeanor showing reduced facial reactivity and slowed thinking. ${ }^{30}$ 
Table 1. Differential diagnoses of depression in cancer patients

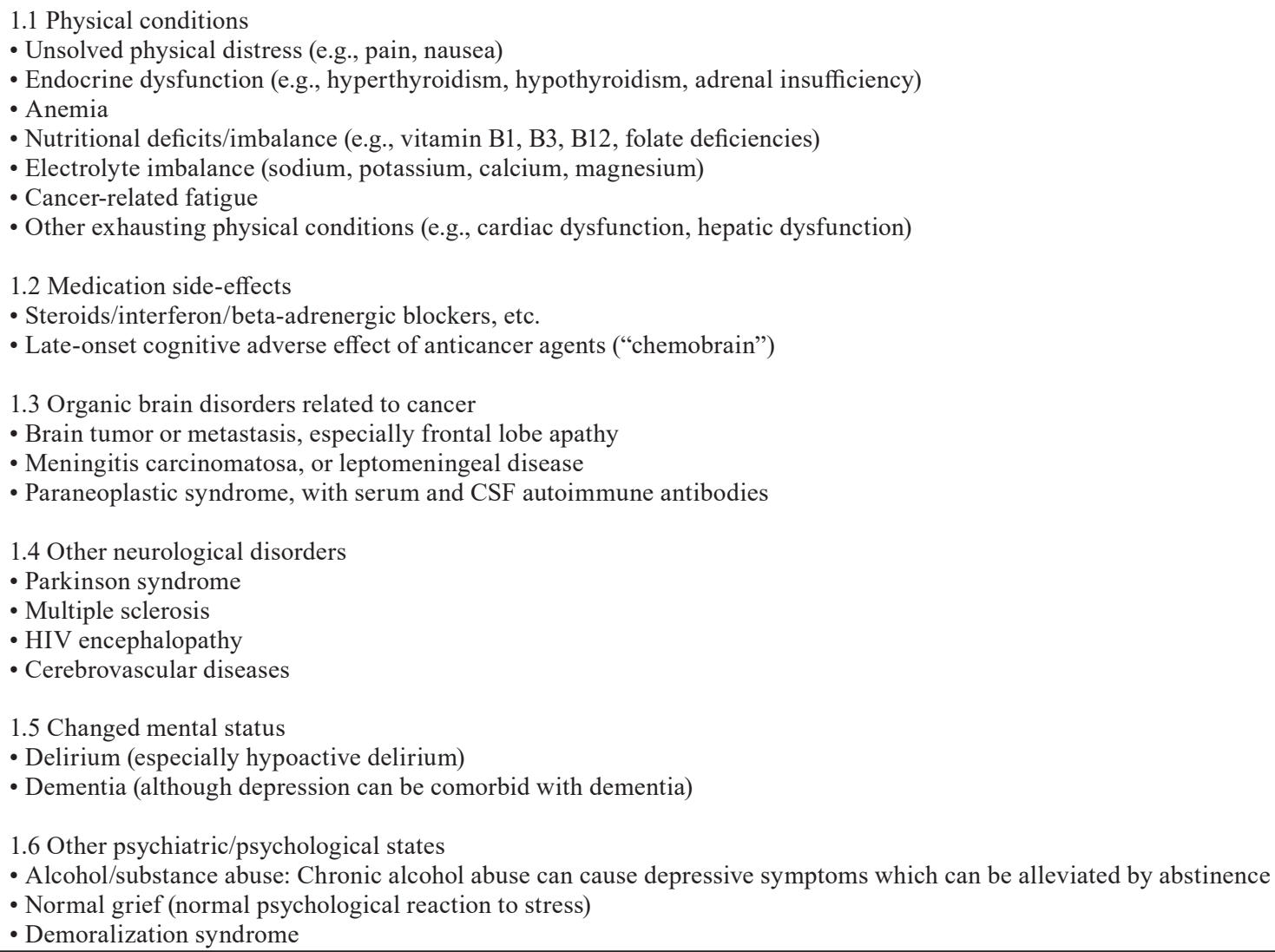

\section{Assessment}

\section{Screening}

Depression is frequently under-recognized and undertreated. Severe depression is more likely to be under-recognized, probably because patients with severe depression tend to express their emotions less than those with milder depression. ${ }^{31}$ Therefore, routine screening is considered vital in oncology practice. The U.S. Preventive Services Task Force recommends a straightforward twoitem screener for major depression that has been proven to be as effective as longer screening instruments. ${ }^{32} \mathrm{~A}$ positive answer to either of the following two questions prompts clinicians to perform a full diagnostic assessment of major depression.

"Over the past 2 weeks, have you ever felt down, depressed, or hopeless?"

"Over the past 2 weeks, have you felt little interest or pleasure in doing things?"

A meta-analysis demonstrated that this simple twoquestion combination facilitated a diagnosis of depression with a positive predictive value (PPV) of $57 \%$ and a negative predictive value (NPV) of $98 \%$. Even a single question (asking either of the two questions above) enabled clinicians to detect depression with a PPV of $44 \%$ and an NPV of $94 \%$ for the "depressed mood" question and a PPV of $48 \%$ and an NPV of $97 \%$ for the "loss-ofinterest" question. ${ }^{33}$

\section{Differential diagnoses}

Many physical and psychological conditions mimic depression. For example, poor appetite, weight loss, and fatigue can be either symptoms due to cancer (and cancer treatments) or depressive symptoms. These are differentiated by assessing the presence of depressive mood or anhedonia. Key differential diagnoses are listed in Table 1.

To exclude differentials, laboratory tests to exclude anemia $(\mathrm{Hb}, \mathrm{Ht})$, electrolyte disturbance $(\mathrm{Na}, \mathrm{K}, \mathrm{Ca}$, $\mathrm{Mg}$ ), hypoglycemia (Glu), and endocrine disorders (thyroid tests, cortisol) are essential. Neuroimaging to screen for intracranial lesions (e.g., brain metastasis or occult cervical infarction) is also important. Clinicians should note that gadolinium-enhancement MRI is necessary to detect subtle brain metastasis and meningitis carcinomatosa. Electroencephalograms (EEGs) are sometimes used if consciousness disturbance is hard to rule out. 


\section{General Management by Primary Care Providers}

Treatment of depression should not target depressive symptoms only, but should also address disease-related and psychosocial unmet needs that contribute to the emergence of depression. These include, but are not limited to, physical symptoms (e.g., pain), insufficient medical information provision or misunderstanding of medical information by patients, unsatisfactory relationships with medical providers, insufficient social support, and other psycho-social issues (e.g., employment problems). These needs should be addressed by a multidisciplinary team in usual practice. Temel et al. demonstrated that, in a sample of patients with metastatic lung cancer, palliative care integrated in oncology practice from the early phase of cancer treatment ("early palliative care") significantly decreased patients' depression and improved QoL and survival, without an increased use of mental health professionals. ${ }^{34}$ Good communication between patients and clinicians is a vital first step for good psychological care. Clinicians' communication skills can be improved through training, and it has been shown that oncologists who received 2 days of communications skills training improved their communication skills, resulting in lower levels of depression in their patients. ${ }^{35}$ For patients with severe psychopathology, more specialized care, including referral to mental health professionals, is required (Fig. 1).

\section{Specialized Care}

Both pharmacotherapy and psychotherapy (psychological treatment) have proven effective for treating depression in cancer patients. Psychotherapy is indicated at all levels of depression severity. Pharmacotherapy is an option for mild to moderate depression and is a requirement for severe depression. All treatments should be tailored based on patients' preferences, physical conditions, and access to care.

\section{Pharmacotherapy}

Key drugs for treating depression are antidepressants. A few randomized controlled trials (RCTs) have demonstrated the effectiveness of antidepressants for depression in cancer patients. ${ }^{36}$ There is no solid evidence that one antidepressant is superior to another in terms of effectiveness; therefore, it is recommended that clinicians select a drug from the perspective of adverse effects and potential

\section{Treatments according to severity}

mild

Normal reactions
to stress

to stress
Adjustment Disorder

Minor/Subthreshold

Depression

severe

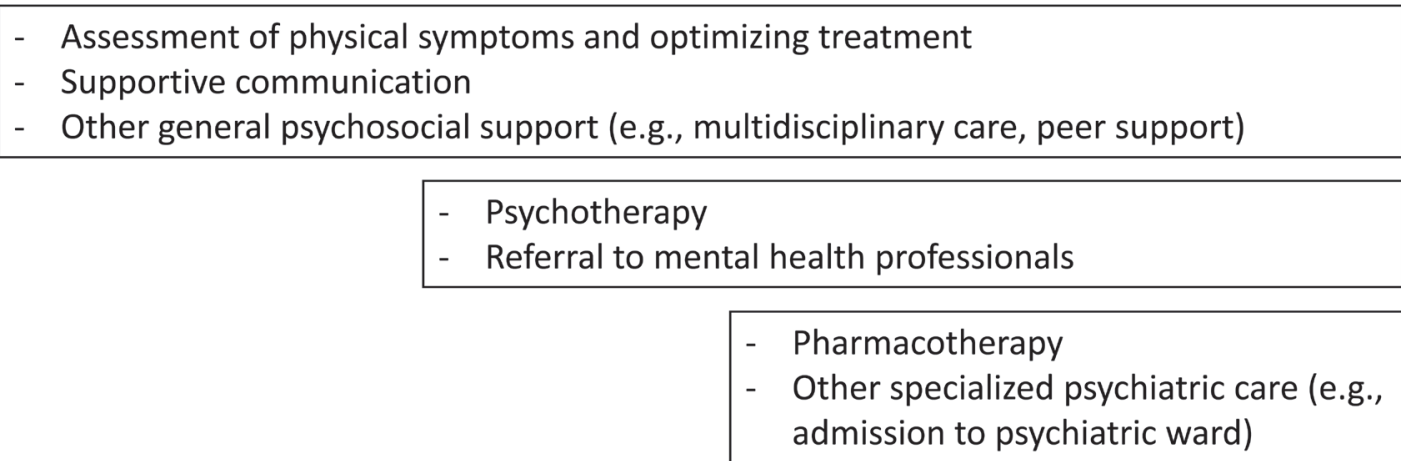

Fig. 1 Treatments according to severity. 
drug-drug interactions. Anxiolytics or neuroleptics may be preferred in situations where a patient has severe depression which needs urgent relief, or that a patient has extremely poor prognosis and cannot wait for weeks. ${ }^{37}$

Anxiolytics and hypnotics, usually benzodiazepines, may be used as adjunctive medication to antidepressants to alleviate distress, anxiety, agitation, and/or sleep problems. Their quick effects are accepted as favorable by patients and clinicians, although their effectiveness for depression in the long term ( $>4$ weeks) has not been proven. Caution is necessary because benzodiazepines may induce delirium in vulnerable patients, such as older patients and those with advanced illness. ${ }^{38}$

Neuroleptics (i.e., antipsychotics, or major tranquilizers) are used either as an augmentation therapy for depression or as an alternative for anxiolytics, especially for patients with severe symptoms which cannot be alleviated by benzodiazepines, or for patients at risk of dependence using benzodiazepines. Neuroleptics do not cause addiction, but benzodiazepines do. Some antipsychotics (e.g., quetiapine, aripiprazole) themselves have antidepressant effects. ${ }^{39,40}$ However, caution is needed because of the elevated risks for mortality and serious complications (e.g., cerebrovascular disease) associated with the use of antipsychotics that have been reported in the elderly population. ${ }^{41}$

\section{Psychotherapy}

There is robust evidence on psychotherapies for patients with cancer. Faller et al. conducted a systematic review of psychological treatments for cancer patients, collecting 198 relevant studies $(n=22,238) .{ }^{42}$ The overall effect sizes were $\mathrm{d}=0.33$ (95\% CI: $0.25-0.41)$ for depression, $\mathrm{d}$ $=0.38(0.29-0.46)$ for anxiety, and $\mathrm{d}=0.29(0.20-0.37)$ for general psychological distress. Longer durations of intervention are associated with more sustained treatment effects, and studies with larger sample sizes tend to have smaller effect sizes. Studies that targeted patients with all levels of psychological distress (in contrast with studies which selected patients with high levels of psychological distress) produced only small effect sizes or resulted in non-significant findings. ${ }^{43}$ Not all patients suffer from psychological distress, and, considering the floor effect, structured psychological treatments perform better than controls when they target selected patients above a certain threshold level of psychological distress. Indeed, in studies of psychological treatments of cancer patients, the severity of psychological symptoms at baseline explained $50 \%$ of the variance of symptom severity after intervention. ${ }^{44}$

In parallel with advances in psychotherapies in general psychiatric practice, newer psychotherapies have been applied and have proven effective in alleviating psychological distress in cancer patients. Mindfulness-based in- terventions have been receiving growing attention. Piet et al. conducted a meta-analysis of mindfulness-based interventions for cancer patients and computed that the effect sizes for anxiety and depression were Hedges' $g$ $=0.37$ and 0.44 , respectively $(P<0.001) .{ }^{45}$ In Keio University Hospital, the author's research group is conducting an RCT of mindfulness-based cognitive therapy for breast cancer patients in collaboration with the Department of Surgery, the Department of Neuropsychiatry, and the Faculty of Nursing and Medical Care (UMIN-CTR: 000016142), following a promising result from a pilot feasibility study. ${ }^{46}$

The use of the telephone and information technology in providing care is another trend in psychological care. Kronke et al. conducted a multicenter RCT examining the effectiveness of care management by nurses and physicians through an automated telephone response system and the internet for cancer patients with either depression or substantial pain. This intervention was found to achieve better results in pain prevalence and severity at 12-month follow-up compared with the control group, and a lower prevalence and severity of depression. ${ }^{47}$ Evidence is scarce on the use of the internet in treating depression in cancer patients. Our research group has embarked on a pilot trial of internet-assisted mindfulness-based cognitive therapy for cancer patients (UMIN000019653).

A recent trend in depression care in cancer practice is that psychotherapies are provided in the context of systematic collaborative care, i.e., they are conducted in conjunction with screening, case management, and medication, rather than being provided separately. The effectiveness of collaborative care has been proved in a large scale RCT ${ }^{48,49}$ In the collaborative care model, primary care providers (usually trained nurses) provide systematic screening and initial management of depression under the supervision of a psychiatrist. The primary care providers deliver brief counseling (e.g., problem-solving therapy) and make referrals to psychiatrists as needed.

\section{Depression in Family Caregivers}

Cancer not only affects the patients themselves but also affects the mental health of their families. A high prevalence of depression among family caregivers of cancer patients has been reported (12.5-27.9\%). ${ }^{50-52}$ Cancer can leave persisting psychological impacts on family members. Family members who have lost their loved ones experience grief, and some suffer from persistent or extremely severe grief symptoms, which is called "complicated grief." The point prevalence of complicated grief in the general Japanese population has been reported as $2.7 \%$, with an additional $25 \%$ with subthreshold complicated grief. Complicated grief persists without significant decrease for up to 10 years after bereavement. ${ }^{53}$ Good end-of-life care for a patient can buffer development of future complicated grief among their family members. 
Fujisawa D: Depression in Cancer Care

Our group has demonstrated that bereaved families who are satisfied with the explanations given by clinicians of the patient's expected outcome are associated with a lower incidence of complicated grief. ${ }^{54}$ Therefore, providing sufficient information to patients' families about expected outcomes and enhancing patients' sense of completion about their life may prevent bereaved family members from developing complicated grief.

\section{Conclusions}

Depression is common among cancer patients and may cause substantial clinical impacts not only to patients themselves but also to their family members. Clinicians should routinely screen cancer patients for comorbid depression and should provide appropriate care on both primary and specialized care levels. Good quality care may be beneficial for cancer patients as well as for their family members.

\section{Conflict of Interest}

The author declares no conflict of interest for this study.

\section{Reference}

1. Fitzmaurice C, Dicker D, Pain A, Hamavid H, Moradi-Lakeh M, MacIntyre MF, Allen C, Hansen G, Woodbrook R, Wolfe C, Hamadeh RR, Moore A, Werdecker A, Gessner BD, Te Ao B, McMahon B, Karimkhani C, Yu C, Cooke GS, Schwebel DC, Carpenter DO, Pereira DM, Nash D, Kazi DS, De Leo D, Plass D, Ukwaja KN, Thurston GD, Yun Jin K, Simard EP, Mills E, Park EK, Catalá-López F, deVeber G, Gotay C, Khan G, Hosgood HD, Santos IS, Leasher JL, Singh J, Leigh J, Jonas JB, Sanabria J, Beardsley J, Jacobsen KH, Takahashi K, Franklin RC, Ronfani L, Montico M, Naldi L, Tonelli M, Geleijnse J, Petzold M, Shrime MG, Younis M, Yonemoto N, Breitborde N, Yip P, Pourmalek F, Lotufo PA, Esteghamati A, Hankey GJ, Ali R, Lunevicius R, Malekzadeh R, Dellavalle R, Weintraub R, Lucas R, Hay R, Rojas-Rueda D, Westerman R, Sepanlou SG, Nolte S, Patten S, Weichenthal S, Abera SF, Fereshtehnejad SM, Shiue I, Driscoll T, Vasankari T, Alsharif U, Rahimi-Movaghar V, Vlassov VV, Marcenes WS, Mekonnen W, Melaku YA, Yano Y, Artaman A, Campos I, MacLachlan J, Mueller U, Kim D, Trillini M, Eshrati B, Williams HC, Shibuya K, Dandona R, Murthy K, Cowie B, Amare AT, Antonio CA, Castañeda-Orjuela C, van Gool CH, Violante F, Oh IH, Deribe K, Soreide K, Knibbs L, Kereselidze M, Green M, Cardenas R, Roy N, Tillmann T, Li Y, Krueger H, Monasta L, Dey S, Sheikhbahaei S, Hafezi-Nejad N, Kumar GA, Sreeramareddy CT, Dandona L, Wang H, Vollset SE, Mokdad A, Salomon JA, Lozano R, Vos T, Forouzanfar M, Lopez A, Murray C, Naghavi M, Global Burden of Disease Cancer Collaboration: The Global Burden of Cancer 2013. JAMA Oncol 2015; 1: 505-527. PMID:26181261

2. Cancer Information Service NCC: Japan. Cancer Registry and Statistics. Cancer Information Service, National Cancer Center, Japan. [Available from: http://ganjoho.jp/reg_stat/statistics/stat/ summary.html]

3. Armes J, Crowe M, Colbourne L, Morgan H, Murrells T, Oakley C, Palmer N, Ream E, Young A, Richardson A: Patients' supportive care needs beyond the end of cancer treatment: a pro- spective, longitudinal survey. J Clin Oncol 2009; 27: 6172-6179. PMID:19884548, DOI:10.1200/JCO.2009.22.5151

4. Harrison SE, Watson EK, Ward AM, Khan NF, Turner D, Adams E, Forman D, Roche MF, Rose PW: Primary health and supportive care needs of long-term cancer survivors: a questionnaire survey. J Clin Oncol 2011; 29: 2091-2098. PMID:21519023

5. Umezawa S, Fujisawa D, Fujimori M, Ogawa A, Matsushima E, Miyashita M: Prevalence, associated factors and source of support concerning supportive care needs among Japanese cancer survivors. Psychooncology 2015; 24: 635-642. PMID:25286187, DOI:10.1002/pon.3702

6. Mehnert A, Koch U, Schulz H, Wegscheider K, Weis J, Faller H, Keller M, Brähler E, Härter M: Prevalence of mental disorders, psychosocial distress and need for psychosocial support in cancer patients - study protocol of an epidemiological multicenter study. BMC Psychiatry 2012; 12: 70. PMID:22747671, DOI:10.1186/1471-244X-12-70

7. Akechi T, Okuyama T, Sugawara Y, Nakano T, Shima Y, Uchitomi Y: Major depression, adjustment disorders, and post-traumatic stress disorder in terminally ill cancer patients: associated and predictive factors. J Clin Oncol 2004; 22: 1957-1965. PMID:15143090, DOI:10.1200/JCO.2004.08.149

8. Fang F, Fall K, Mittleman MA, Sparén P, Ye W, Adami HO, Valdimarsdóttir U: Suicide and cardiovascular death after a cancer diagnosis. N Engl J Med 2012; 366: 1310-1318. PMID:22475594, DOI:10.1056/NEJMoa1110307

9. Mitchell AJ, Chan M, Bhatti H, Halton M, Grassi L, Johansen C, Meader N: Prevalence of depression, anxiety, and adjustment disorder in oncological, haematological, and palliative-care settings: a meta-analysis of 94 interview-based studies. Lancet Oncol 2011; 12: 160-174. PMID:21251875, DOI:10.1016/S14702045(11)70002-X

10. Fujisawa D, Park S, Kimura R, Suyama I, Koyama Y, Takeuchi M, Yoshikawa H, Hashiguchi S, Shirahase J, Kato M, Takeda J, Kashima H: Unmet supportive needs of cancer patients in an acute care hospital in Japan - a census study. Support Care Cancer 2010; 18: 1393-1403. PMID:19841949

11. Mehnert A, Brähler E, Faller H, Härter M, Keller M, Schulz H, Wegscheider K, Weis J, Boehncke A, Hund B, Reuter K, Richard M, Sehner S, Sommerfeldt S, Szalai C, Wittchen HU, Koch U: Four-week prevalence of mental disorders in patients with cancer across major tumor entities. J Clin Oncol 2014; 32: 3540-3546. PMID:25287821, DOI:10.1200/JCO.2014.56.0086

12. Akechi T, Okamura H, Nishiwaki Y, Uchitomi Y: Psychiatric disorders and associated and predictive factors in patients with unresectable nonsmall cell lung carcinoma: a longitudinal study. Cancer 2001; 92: 2609-2622. PMID:11745196, DOI:10.1002/10970142(20011115)92:10<2609::AID-CNCR1614>3.0.CO;2-K

13. Gonçalves V, Jayson G, Tarrier N: A longitudinal investigation of psychological morbidity in patients with ovarian cancer. Br J Cancer 2008; 99: 1794-1801. PMID:19002175

14. Uchitomi Y, Mikami I, Nagai K, Nishiwaki Y, Akechi T, Okamura $\mathrm{H}$ : Depression and psychological distress in patients during the year after curative resection of non-small-cell lung cancer. J Clin Oncol 2003; 21: 69-77. PMID:12506173, DOI:10.1200/ JCO.2003.12.139

15. Fujisawa D, Inoguchi $\mathrm{H}$, Shimoda $\mathrm{H}$, Yoshiuchi K, Inoue S, Ogawa A, Okuyama T, Akechi T, Mimura M, Shimizu K, Uchitomi Y: Impact of depression on health utility value in cancer patients. Psychooncology 2016; 25: 491-495. PMID:26283141

16. Liang X, Margolis KL, Hendryx M, Reeves K, WassertheilSmoller S, Weitlauf J, Danhauer SC, Chlebowski RT, Caan B, Qi L, Lane D, Lavasani S, Luo J: Effect of depression before breast cancer diagnosis on mortality among postmenopausal women. Cancer 2017; 123: 3107-3115. PMID:28387934, DOI:10.1002/ cncr.30688 
17. Suppli NP, Johansen C, Kessing LV, Toender A, Kroman N, Ewertz M, Dalton SO: Survival after early-stage breast cancer of women previously treated for depression: A nationwide Danish cohort study. J Clin Oncol 2017; 35: 334-342. PMID:28095267, DOI:10.1200/JCO.2016.68.8358

18. Barber B, Dergousoff J, Slater L, Harris J, O'Connell D, ElHakim H, Biron VL, Mitchell N, Seikaly H: Depression and survival in patients with head and neck cancer: A systematic review. JAMA Otolaryngol Head Neck Surg 2016; 142: 284-288. PMID:26796781, DOI:10.1001/jamaoto.2015.3171

19. Colleoni M, Mandala M, Peruzzotti G, Robertson C, Bredart A, Goldhirsch A: Depression and degree of acceptance of adjuvant cytotoxic drugs. Lancet 2000; 356: 1326-1327. PMID:11073026, DOI:10.1016/S0140-6736(00)02821-X

20. Thorsen L, Nystad W, Stigum H, Dahl O, Klepp O, Bremnes RM, Wist E, Fosså SD: The association between self-reported physical activity and prevalence of depression and anxiety disorder in long-term survivors of testicular cancer and men in a general population sample. Support Care Cancer 2005; 13: 637-646. PMID:15756585, DOI:10.1007/s00520-004-0769-0

21. Fujisawa D, Umezawa S, Basaki-Tange A, Fujimori M, Miyashita M: Smoking status, service use and associated factors among Japanese cancer survivors - a web-based survey. Support Care Cancer 2014; 22: 3125-3134. PMID:24848577, DOI:10.1007/ s00520-014-2284-2

22. Fujisawa D, Temel JS, Traeger L, Greer JA, Lennes IT, Mimura M, Pirl WF: Psychological factors at early stage of treatment as predictors of receiving chemotherapy at the end of life. Psychooncology 2015; 24: 1731-1737. PMID:25959002, DOI:10.1002/ pon. 3840

23. Park S, Kang CH, Hwang Y, Seong YW, Lee HJ, Park IK, Kim YT: Risk factors for postoperative anxiety and depression after surgical treatment for lung cancer. Eur J Cardiothorac Surg 2016; 49: e16-e21. PMID:26410631, DOI:10.1093/ejcts/ezv336

24. Barber B, Dergousoff J, Nesbitt M, Mitchell N, Harris J, O'Connell D, Côté D, Biron V, Seikaly H: Depression as a predictor of postoperative functional performance status (PFPS) and treatment adherence in head and neck cancer patients: a prospective study. J Otolaryngol Head Neck Surg 2015; 44: 38. PMID:26385356, DOI:10.1186/s40463-015-0092-4

25. Ghoneim MM, O'Hara MW: Depression and postoperative complications: an overview. BMC Surg 2016; 16: 5. PMID:26830195

26. Breitbart W, Rosenfeld B, Pessin H, Kaim M, Funesti-Esch J, Galietta M, Nelson CJ, Brescia R: Depression, hopelessness, and desire for hastened death in terminally ill patients with cancer. JAMA 2000; 284: 2907-2911. PMID:11147988, DOI:10.1001/ jama.284.22.2907

27. Thornton LM, Andersen BL, Schuler TA, Carson WE: A psychological intervention reduces inflammatory markers by alleviating depressive symptoms: secondary analysis of a randomized controlled trial. Psychosom Med 2009; 71: 715-724. PMID:19622708, DOI:10.1097/PSY.0b013e3181b0545c

28. Orgnization WH: International Statistical Classification of Diseases and Related Health Problems 10th Revision 1990 [Available from: http://www.who.int/classifications/icd/en/].

29. American Psychiatric Association: Diagnostic and statistical manual of mental disorders: DSM-5. Washington, D.C.: American Psychiatric Association; 2013.

30. Akechi T, Ietsugu T, Sukigara M, Okamura H, Nakano T, Akizuki N, Okamura M, Shimizu K, Okuyama T, Furukawa TA, Uchitomi Y: Symptom indicator of severity of depression in cancer patients: a comparison of the DSM-IV criteria with alternative diagnostic criteria. Gen Hosp Psychiatry 2009; 31: 225-232. PMID:19410101, DOI:10.1016/j.genhosppsych.2008.12.004

31. Passik SD, Dugan W, McDonald MV, Rosenfeld B, Theobald DE, Edgerton S: Oncologists' recognition of depression in their patients with cancer. J Clin Oncol 1998; 16: 1594-1600. PMID:9552071, DOI:10.1200/JCO.1998.16.4.1594

32. Siu AL, Bibbins-Domingo K, Grossman DC, Baumann LC, Davidson KW, Ebell M, García FA, Gillman M, Herzstein J, Kemper AR, Krist AH, Kurth AE, Owens DK, Phillips WR, Phipps MG, Pignone MP, US Preventive Services Task Force (USPSTF): Screening for depression in adults: US Preventive Services Task Force recommendation statement. JAMA 2016; 315: 380-387. PMID:26813211, DOI:10.1001/jama.2015.18392

33. Mitchell AJ: Are one or two simple questions sufficient to detect depression in cancer and palliative care? A Bayesian metaanalysis. Br J Cancer 2008; 98: 1934-1943. PMID:18506146, DOI:10.1038/sj.bjc.6604396

34. Temel JS, Greer JA, Muzikansky A, Gallagher ER, Admane S, Jackson VA, Dahlin CM, Blinderman CD, Jacobsen J, Pirl WF, Billings JA, Lynch TJ: Early palliative care for patients with metastatic non-small-cell lung cancer. N Engl J Med 2010; 363: 733-742. PMID:20818875, DOI:10.1056/NEJMoa1000678

35. Fujimori M, Shirai Y, Asai M, Kubota K, Katsumata N, Uchitomi Y: Effect of communication skills training program for oncologists based on patient preferences for communication when receiving bad news: a randomized controlled trial. J Clin Oncol 2014; 32: 2166-2172. PMID:24912901, DOI:10.1200/JCO.2013.51.2756

36. Ostuzzi G, Matcham F, Dauchy S, Barbui C, Hotopf M: Antidepressants for the treatment of depression in people with cancer. Cochrane Database Syst Rev 2015; CD011006. PMID:26029972

37. Okamura M, Akizuki N, Nakano T, Shimizu K, Ito T, Akechi T, Uchitomi Y: Clinical experience of the use of a pharmacological treatment algorithm for major depressive disorder in patients with advanced cancer. Psychooncology 2008; 17: 154-160. PMID:17461435, DOI:10.1002/pon.1213

38. Gaudreau JD, Gagnon P, Roy MA, Harel F, Tremblay A: Association between psychoactive medications and delirium in hospitalized patients: a critical review. Psychosomatics 2005; 46: 302-316. PMID:16000673, DOI:10.1176/appi.psy.46.4.302

39. Sanford M: Quetiapine extended release: adjunctive treatment in major depressive disorder. CNS Drugs 2011; 25: 803-813. PMID:21870891, DOI:10.2165/11207280-000000000-00000

40. Komossa K, Depping AM, Gaudchau A, Kissling W, Leucht S: Second-generation antipsychotics for major depressive disorder and dysthymia. Cochrane Database Syst Rev 2010; CD008121. PMID:21154393

41. Mittal V, Kurup L, Williamson D, Muralee S, Tampi RR: Risk of cerebrovascular adverse events and death in elderly patients with dementia when treated with antipsychotic medications: a literature review of evidence. Am J Alzheimers Dis Other Demen 2011; 26: 10-28. PMID:21282274, DOI:10.1177/1533317510390351

42. Faller H, Schuler M, Richard M, Heckl U, Weis J, Küffner R: Effects of psycho-oncologic interventions on emotional distress and quality of life in adult patients with cancer: systematic review and meta-analysis. J Clin Oncol 2013; 31: 782-793. PMID:23319686, DOI:10.1200/JCO.2011.40.8922

43. Sheard T, Maguire P: The effect of psychological interventions on anxiety and depression in cancer patients: results of two meta-analyses. Br J Cancer 1999; 80: 1770-1780. PMID:10468295, DOI:10.1038/sj.bjc.6690596

44. Linden W, Girgis A: Psychological treatment outcomes for cancer patients: what do meta-analyses tell us about distress reduction? Psychooncology 2012; 21: 343-350. PMID:21882287, DOI:10.1002/pon.2035

45. Piet J, Würtzen H, Zachariae R: The effect of mindfulness-based therapy on symptoms of anxiety and depression in adult cancer patients and survivors: a systematic review and meta-analysis. J Consult Clin Psychol 2012; 80: 1007-1020. PMID:22563637, DOI:10.1037/a0028329

46. Park S, Sado M, Fujisawa D, Sato Y, Takeuchi M, Ninomiya A, Takahashi M, Yoshimura K, Jinno H, Takeda Y. Mindfulness- 
based Cognitive Therapy for Japanese Breast Cancer Patients - a Feasibility Study. Jap J Clin Oncology (in press).

47. Kroenke K, Theobald D, Wu J, Norton K, Morrison G, Carpenter $\mathrm{J}, \mathrm{Tu} \mathrm{W}$ : Effect of telecare management on pain and depression in patients with cancer: a randomized trial. JAMA 2010; 304: 163171. PMID:20628129, DOI:10.1001/jama.2010.944

48. Walker J, Hansen CH, Martin P, Symeonides S, Gourley C, Wall L, Weller D, Murray G, Sharpe M, SMaRT (Symptom Management Research Trials) Oncology-3 Team: Integrated collaborative care for major depression comorbid with a poor prognosis cancer (SMaRT Oncology-3): a multicentre randomised controlled trial in patients with lung cancer. Lancet Oncol 2014; 15: 1168-1176. PMID:25175097, DOI:10.1016/S1470-2045(14)70343-2

49. Sharpe M, Walker J, Holm Hansen C, Martin P, Symeonides S, Gourley C, Wall L, Weller D, Murray G, SMaRT (Symptom Management Research Trials) Oncology-2 Team: Integrated collaborative care for comorbid major depression in patients with cancer (SMaRT Oncology-2): a multicentre randomised controlled effectiveness trial. Lancet 2014; 384: 1099-1108. PMID:25175478

50. Asai M, Akechi T, Nakano T, Shimizu K, Umezawa S, Akizuki N, Uchitomi Y: Psychiatric disorders and background characteristics of cancer patients' family members referred to psychiat- ric consultation service at National Cancer Center Hospitals in Japan. Palliat Support Care 2008; 6: 225-230. PMID:18662415, DOI:10.1017/S1478951508000369

51. Lee CY, Lee Y, Wang LJ, Chien CY, Fang FM, Lin PY: Depression, anxiety, quality of life, and predictors of depressive disorders in caregivers of patients with head and neck cancer: A six-month follow-up study. J Psychosom Res 2017; 100: 29-34. PMID:28789790, DOI:10.1016/j.jpsychores.2017.07.002

52. Tan JY, Molassiotis A, Lloyd-Williams M, Yorke J: Burden, emotional distress and quality of life among informal caregivers of lung cancer patients: An exploratory study. Eur J Cancer Care (Engl) 2017. PMID:28417550

53. Fujisawa D, Miyashita M, Nakajima S, Ito M, Kato M, Kim Y: Prevalence and determinants of complicated grief in general population. J Affect Disord 2010; 127: 352-358. PMID:20580096, DOI:10.1016/j.jad.2010.06.008

54. Miyajima K, Fujisawa D, Yoshimura K, Ito M, Nakajima S, Shirahase J, Mimura M, Miyashita M: Association between quality of end-of-life care and possible complicated grief among bereaved family members. J Palliat Med 2014; 17: 1025-1031. PMID:25050607, DOI:10.1089/jpm.2013.0552 